\title{
Stimulation of Adenylate Cyclase in Relation to Dopamine-Induced Long-Term Enhancement (LTE) of Muscarinic Depolarization in the Rabbit Superior Cervical Ganglion
}

\author{
Sumiko Mochida, Haruo Kobayashi, and Benjamin Libet' \\ Department of Physiology, Tokyo Medical College, Tokyo 160, Japan, and 'Department of Physiology, School of \\ Medicine, University of California, San Francisco, California 94143
}

Dopamine (DA) induction of the long-term enhancement (LTE) of the slow muscarinic depolarizing response to methacholine (MCh), equivalent to the slow EPSP (S-EPSP), was previously found to be mimicked by exogenous cyclic AMP (CAMP) in the rabbit superior cervical ganglion (SCG). DA-induced LTE of the S-EPSP was shown to be depressed by some DA antagonists. We now show that DA (15 $\mu \mathrm{M})$, its analog, 2-amino-6,7-dihydroxy-1,2,3,4-tetrahydronaphthalene (ADTN), and a $D_{2}$ receptor antagonist, metoclopramide, each can induce both LTE of MCh depolarization and an increase in ganglionic cAMP. Conversely, antagonists of DAinduced LTE also depress DA-induced rises in CAMP; these antagonists include haloperidol $(1 \mu \mathrm{M})$, both $(+)$ and $(-)$ enantiomers of butaclamol (0.7-7 $\mu \mathrm{M})$, flupenthixol (1 $\mu \mathrm{M})$, and $(+)-R-8-c h l o r o-2,3,4,5-t e t r a h y d r o-3-m e t h y l-5-p h e n y l-1 H$ 3-benzazepine-7-ol (SCH-23390) (7 $\mu \mathrm{M})$. The selective $\mathrm{D}_{2}$ antagonists sulpiride $(10 \mu \mathrm{M})$ and domperidone $(10 \mu \mathrm{M})$ affect neither DA action. Alpha-2 adrenergic agonists ( $\alpha$-methylnorepinephrine and clonidine) produce no LTE; $\alpha$-antagonist dihydroergotamine (35 $\mu \mathrm{M}$ ) does not affect either DA action, although it can completely block the hyperpolarizing response to DA or other catecholamines. Beta-antagonist propranolol (5 $\mu \mathrm{M})$ partially depresses DA-induced rises in CAMP but has no effect on the DA-induced LTE. (Butaclamol and propranolol in combination can completely block the cAMP rise induced by DA.) Beta-agonist isoproterenol can induce appreciable LTE of MCh depolarization, but this LTE is not depressed by propranolol (10 $\mu \mathrm{M})$. Isoproterenol can elicit a substantial rise in CAMP. We conclude that LTE of slow muscarinic depolarizing responses is induced via activation of a DA receptor that is coupled to adenylate cyclase and resembles, but is not identical to, $D_{1}$ receptors described in the brain. The induction of LTE by isoproterenol may reflect an ability to activate this DA receptor to some extent, rather than its additional activation of a $\beta$-receptor. In contrast to

\footnotetext{
Received May 6, 1985; revised Aug. 18, 1986; accepted Aug. 26, 1986.

The authors are grateful to Professor Tsuneo Tosaka for his valuable comments on this paper. This work was supported by grants to one of the authors (H.K.) for the Special Research Project on Metabolic Responses and Their Disorders $(56220035,57213038$, and 58105001) from the Ministry of Education, Science and Culture of Japan, and to another (B.L.) from the USPHS (NS-00884).

Correspondence should be addressed to Dr. Sumiko Mochida, Department of Physiology, Tokyo Medical College, 1-1, Shinjuku-6-chome, Shinjuku-ku, Tokyo 160, Japan.

Copyright (C) 1987 Society for Neuroscience $0270-6474 / 87 / 020311-08 \$ 02.00 / 0$
}

the cAMP produced at the DA receptor, cAMP formed via activation of $\beta$-receptors in this ganglion appears to be ineffective for inducing LTE of muscarinic responses.

Dopamine (DA) has been shown to induce in the rabbit sympathetic ganglia a long-lasting augmentation, continuing for hours, of the slow muscarinic depolarizing response to ACh or to the muscarinic agonists acetyl- $\beta$-methylcholine (MCh) and bethanechol (BCh) (Libet and Tosaka, 1970; Libet et al., 1975; Libet, 1979a). The slow (s-) IPSP and s-EPSP elicited by orthodromic test volleys also exhibited a large augmentation following exposure of the ganglion to DA in the presence of an inhibitor of catechol-o-methyltransferase (COMT) 3',4'-dihydroxy-2-methylpropiophenone (U-0521) (Ashe and Libet, 1981). A similar long-lasting change ("long-term enhancement" or LTE) of s-EPSP was seen after a conditioning train of preganglionic volleys, even when testing heterosynaptically in another unconditioned, preganglionic nerve (Mochida and Libet, 1983, 1985). The ability, first, of DA to stimulate adenylate cyclase in sympathetic ganglia of at least some mammalian species (Kebabian and Greengard, 1971; Wamsley et al., 1980) and, sccond, of cAMP, whether applied extracellularly (Libet et al., 1975) or intracellularly (Kobayashi et al., 1978), to mimic the enhancing action of DA, led to the hypothesis that cAMP is the intracellular mediator of the neuronal change responsible for the DA-induced LTE (Libet et al., 1975; Libet, 1979b). Pharmacological antagonists of DA receptors, particularly of $D_{1}$ type, were indeed found to selectively depress the DA-induced LTE (Ashe and Libet, 1981), as well as the neurally conditioned LTE of s-EPSP responses (Mochida and Libet, 1983), while adrenergic antagonists were relatively ineffective.

The present investigation attempts to establish more definitely and specifically the identity of the postsynaptic receptors responsible for the DA induction of LTE of the slow muscarinic depolarization. The capabilities of various agonist and antagonist agents with respect to both actions of DA-the induction of LTE and the stimulation of adenylate cyclase (as indicated by changes in the ganglionic cAMP content)-were compared for the same superior cervical sympathetic ganglion in the rabbit. The results obtained provide evidence that both actions are due to the activation of one and the same kind of receptor, which resembles the $D_{1}$ type and is distinguished from $D_{2}$ as well as from $\alpha$ - and $\beta$-adrenergic receptors. Preliminary reports of this work have been presented in abstract form (Mochida et al., 1981a, b; Kobayashi et al., 1982). 


\section{Materials and Methods}

Superior cervical ganglia (SCG) were excised from male white rabbits (weighing 1.8-2.2 kg) under light urethane anesthesia and placed in oxygenated modified Krebs solution with the following composition: $\mathrm{NaCl}, 136.0 \mathrm{~mm}, \mathrm{KCl}, 5.94 \mathrm{~mm}, \mathrm{CaCl}_{2}, 2.54 \mathrm{~mm}, \mathrm{MgCl}_{2}, 1.2 \mathrm{~mm}$, glucose, $11.0 \mathrm{~mm}$, and Na-HEPES, $3.0 \mathrm{~mm}$; pH 7.4. The connective tissue and the sheath surrounding the ganglion were carefully removed before all electrophysiological and biochemical studies.

Electrophysiological recordings and tests. Extracellular potentials were recorded using a sucrose-gap method (Kosterlitz et al., 1968; Wallis et al., 1975; modified by Libet and Tosaka, 1970; Libet et al., 1975). The ganglion compartment, $0.3 \mathrm{ml}$, was perfused continuously with oxygenated Krebs solution at about $1 \mathrm{ml} / \mathrm{min}$; D-tubocurarine, $30 \mu \mathrm{g} / \mathrm{ml}$, was routinely present to minimize any nicotinic responses. The test response was the slow depolarization of the ganglion cells elicited by the muscarinic agonist $\mathrm{MCh}$. MCh and other test agents were dissolved in a small volume $(0.1 \mathrm{ml})$ of Krebs solution and rapidly injected into the line of perfusion at a point close to the chamber. The concentration of agents in the chamber after the injection was estimated by the following procedure, based on a simulation test (Tanaka, 1974): The chamber (with no ganglion mounted) was perfused by distilled water at the same rate $(1 \mathrm{ml} / \mathrm{min})$ as in the actual experiments and known amounts (in micromoles per $0.1 \mathrm{ml}$ ) of $\mathrm{KCl}$ were injected into the perfusion line. At $0.5,1,2,5$, and $10 \mathrm{~min}$ after the injection, $50 \mu \mathrm{l}$ of perfusate in the chamber was sampled and the concentration of $\mathrm{KCl}$ present, as determined by atomic absorption spectrophotometry, was consistently found to be, respectively, $2.1,6.2,3.6,2.0$, and $0 \%$ of the concentration initially injected. The peak concentrations of other test substances in the chamber at $1 \mathrm{~min}$ were assumed to bear a similar relationship to that injected and were calculated accordingly. All recordings were made at room temperature $\left(22-25^{\circ} \mathrm{C}\right)$.

Variable hyperpolarizing components may also be elicited by cholinergic agonists; changes in such hyperpolarizing components can produce corresponding changes in the form and amplitude of the slow muscarinic depolarization with which they overlap, thus complicating the results. An initial hyperpolarizing component, equivalent to the s-IPSP and largely attributable to the action of endogenous DA released from the small, intensely fluorescent (SIF) interneurons (Libet, 1970; Libet and Tosaka, 1970; Libct and Owman, 1974), could be eliminated by pretreating the ganglion with $\mathrm{BCh}(100 \mu \mathrm{g} / \mathrm{ml}$ for $15 \mathrm{~min}$, followed by complete washout, then immersion in Krebs solution for about $90 \mathrm{~min}$; Libet et al., 1975). Such exposure to BCh depletes the functionally releasable DA from the SIF interneurons and depresses the s-IPSP (Libet and Owman, 1974). A later, secondary hyperpolarizing component, due possibly to the action of norepinephrine released dendritically from neighboring ganglion cells (Ashe and Libet, 1979; Libet, 1979a) could be eliminated by a pretreatment with bretylium: The drug was injected intravenously ( $4 \mathrm{mg} / \mathrm{kg}$ body weight) approximately $1 \mathrm{hr}$ prior to the dissection of the ganglia and $6 \mu \mathrm{g} / \mathrm{ml}$ was further included in the bathing medium until the ganglion was mounted in the sucrose-gap chamber. With these combined pretreatments with $\mathrm{BCh}$ and bretylium, the depolarizing responses to the test application of $\mathrm{MCh}$ became more smoothly shaped, devoid of the above hyperpolarizing inflections.

Other minor inflections in the depolarizing responses to $\mathrm{MCh}$, such as those visible in Figures 2 and 3, are different from the large and changeable inflections that we refer to as initial and secondary hyperpolarization, which are removed by the treatments with BCh and bretylium. These minor inflections are presumably variables that are due to the rate of penetration of $\mathrm{MCh}$ into the surface neuronal elements in the ganglion and they do not change in any regular way with repeated tests or with the application of DA. Many responses to MCh show no such inflections at all, but still show the typical LTE following exposure to DA. Consequently, there is no evidence to support the possibility that the enhancement of the MCh depolarization is due to an elimination of hyperpolarizing components.

The LTE effect of DA on the muscarinic slow depolarization was observed by comparing the amplitudes of responses to a test dose of MCh before and at roughly $30 \mathrm{~min}$ intervals after a temporary exposure to DA. MCh doses were usually $50-100 \mu \mathrm{g}$ in $0.1 \mathrm{ml}$, i.e., about $2.5-5$ mM, producing peak concentrations of $M C h$ in the chamber that were estimated to be 150-300 $\mu \mathrm{M}$. The COMT inhibitor U-0521 (300 $\mu \mathrm{M})$ was present in the perfusate starting $30 \mathrm{~min}$ in advance of the application of DA, continuing until 10-15 min after the DA. Although U-0521 may have improved the consistency of the DA action on MCh depolarization,
Table 1. Effects of frequent additives on increases in cAMP content

\begin{tabular}{lrr} 
Additions & $\begin{array}{l}\text { Percent- } \\
\text { age } \\
\text { increase }^{a}\end{array}$ \\
\hline $\begin{array}{l}\text { Theophylline }(5 \mathrm{mM}) \text {, ascorbate }(300 \mu \mathrm{M}) \\
\text { Theophylline, ascorbate, and } \mathrm{U}-0521(300 \mu \mathrm{M})\end{array}$ & 3 & $+2 \pm 5$ \\
$\begin{array}{l}\text { Theophylline, ascorbate, }(+) \text {-butaclamol }(7 \mu \mathrm{M}) \\
\text { Theophylline, ascorbate, U-0521, }(+) \text {-butaclamol } \\
(7 \mu \mathrm{M})\end{array}$ & 3 & $-3 \pm 3$ \\
& 3 & $+10 \pm 8$
\end{tabular}

Percentage increase in cAMP relative to paired ganglia treated as general control group (no additives, earlier freezing).

${ }^{a}$ Expressed as mean and SEM.

it was not essential for this (Libet and Tosaka, 1970); U-0521 appears to be more essential when DA must penetrate to the larger number of the cells within the ganglion at $37^{\circ} \mathrm{C}$, as when testing for effects on surface-recorded s-EPSP (Ashe and Libet, 1981) and on the cAMP content of the whole ganglion. To avoid additional switching of perfusates, doses of DA ( $5 \mu \mathrm{g}$ per $0.1 \mathrm{ml}$, or $250 \mu \mathrm{M}$ concentration) were injected into the perfusion line 5 times at $2 \mathrm{~min}$ intervals; this procedure would produce and maintain an estimated concentration of DA of about $15 \mu \mathrm{M}$ during the $8 \mathrm{~min}$.

The DA-induced LTE process is a particularly labile one and was not exhibited by all ganglia tested (see Results) unless the following precautions were taken. It appeared more consistently when ganglia were kept well circulated with blood until the time of excision from the animal, and when the time spent in vitro before applying DA did not exceed 2-3 hr. Mechanical stretching or distortion of the ganglia had also to be avoided during excision, desheathing, and mounting in the chamber (Ashe and Libet, 1981). According to our present experience, paired ganglia excised from the same animal and treated as identically as possible tend to exhibit relatively similar enhancing effects from DA (see Results). Therefore, potential antagonists that might depress the DA-induced LTE action were always tested on such paired ganglia; i.e., the DA-induccd change in $\mathrm{MCh}$ responses in the ganglion with antagonist present was compared to the DA effect in the paired control ganglion without antagonist. Those experiments in which the control ganglion itself did not show a substantial enhancement of MCh responses after the use of DA were discarded as inadequate tests of a depressant action by an antagonist.

Biochemical measurement of $C A M P$. To stabilize the cAMP levels at the baseline value, a set of paired ganglia, trimmed of pre- and postganglionic nerves, was left in the Krebs solution for $30 \mathrm{~min}$ after removing the sheath. To determine the baseline value, one of these ganglia was quickly frozen on the dry-ice/acetone immediately after this standing period. The other test ganglion was further preincubated at $37^{\circ} \mathrm{C}$ with theophylline $(5 \mathrm{~mm})$ for $30 \mathrm{~min}$, after which $\mathrm{U}-0521(300 \mu \mathrm{M})$ was added. At the end of another $30 \mathrm{~min}$, the ganglion additionally received $\mathrm{DA}$ and $\mathrm{Na}$-ascorbate $(6 \times$ the DA concentration to minimize the oxidative destruction of DA during incubation) at the desired final concentration and was further incubated for another $30 \mathrm{~min}$. Immediately afterwards, the ganglion was rapidly frozen. Both ganglia were homogenized with cold $6 \%$ trichloroacetic acid (TCA) and centrifuged for 25 min at $3500 \mathrm{rpm}$. After the TCA was removed from the supernatant by shaking it with water-saturated ether, the supernatant was lyophilized. It was later dissolved in $50 \mathrm{~mm}$ Tris/EDTA buffer and assayed for cAMP by means of the competitive protein-binding method of Gilman (1970). Protein determination in the precipitates was made using the method of Lowry et al. (1951).

When observing the effects of various antagonists on cAMP synthesis, the increase in the member of the paired ganglia that was treated with DA in the presence of an antagonist, present since the time immediately after dissection, was compared with the baseline value in the contralateral ganglion (with no DA or antagonist) and was expressed as the percentage increase over the baseline value. The adequacy of the baseline value obtained from 1 of the paired ganglia with no additive drugs as the control for this series of experiments was demonstrated by further tests (Table 1), which showed that (1) theophylline and ascorbate did not produce any appreciable change in the baseline value for the paired ganglia that were otherwise treated like the control ganglia above; (2) 


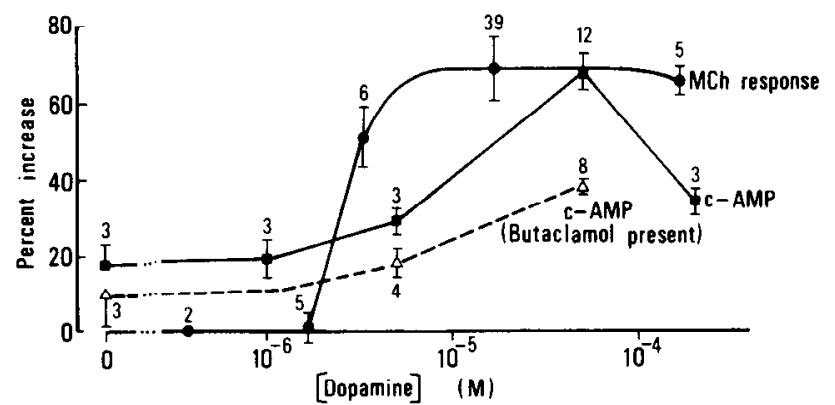

Figure 1. Stimulation by dopamine (DA) of the production of ITE for MCh depolarization and cAMP accumulation. MCh responses (filled circles) were obtained as percentage increases in the amplitude of $\mathrm{MCh}$ induced depolarization after a brief exposure to DA at various concentrations, as compared to that before DA. cAMP changes were measured in the absence (filled squares) and presence (open triangles, dashed line) of $7 \mu \mathrm{M}(+)$-butaclamol and expressed as the percentage increase over the baseline value in the paired ganglion (see Materials and Methods). Each data point represents the mean and SEM of several determinations, as indicated by the numbers.

U-0521 (in addition to the above additives) brought about only a small increase in cAMP content. The effect of $(+)$-butaclamol on this small increase was in the direction of at least partially depressing it. An absence of complete suppression could be due to the possibility that the increase was partly $\beta$-adrenergic in nature (see Discussion); (3) (+)-butaclamol $(7 \mu \mathrm{M})$ by itself did not reduce the cAMP reference level of control ganglia in a nonspecific fashion. The statistical significance of differences was determined, wherever necessary, by $t$ tests.

We are grateful for the gifts of the following materials: $\alpha$-methylnorepinephrine from Hoechst AG, clonidine from Boehringer Ingelheim, haloperidol from Dai-Nippon Pharmaceutical Co., sulpiride from Fujisawa Pharmaceutical Co., domperidone from Janssen, (+)- and (-)butaclamol from Ayerst Research Laboratories, flupenthixol (racemic form) from Takeda Pharmaceutical Co., dihydroergotamine from Sandoz, propranolol from Sumitomo Chemicals, U-0521 from Upjohn, bethanechol from Eizai Pharmaceutical Co., bretylium tosylate from Arnar-Stone Laboratories, ADTN from Dr. G. N. Woodruff, University of Southampton, and SCH-23390 from Dr. A. Barnett, Schering-Plough Corp.

\section{Results}

\section{Long-term enhancement (LTE) of muscarinic slow depolarization by $D A$ and related substances}

Temporary exposure to DA produced a substantial increase in subsequent tests for slow depolarizing responses to MCh. In the tests with 167 pairs of ganglia, 124 (74\%) exhibited an appreciable increase in the control side (subjected to the "standard" DA treatment; see Materials and Methods) of the pairs. In the rest (43 ganglia; $26 \%$ ), no appreciable increase was observed. In those ganglia that produced no LTE, there appeared to be indications of a lack of necessary precautions (see Materials and Methods) to ensure the consistency of the DA effects. Any tests for the effectiveness of antagonists, etc., have therefore been performed only in ganglia whose paired counterparts (control sides) produced a substantial LTE.

DA was tested at estimated concentrations (see Materials and Methods) between 0.3 and $150 \mu \mathrm{M}$ (Fig. 1). LTE was observed after treatment by DA above $1.5 \mu \mathrm{M}$. The degree of developed LTE was not linearly proportional to DA concentration, but rather exhibited a rapid rise to the maximum within a narrow range between 1.5 and $15 \mu \mathrm{M}$ DA. Maximal enhancement of MCh depolarization was obtained with DA at $15 \mu \mathrm{M}$ or more. U-0521 alone did not produce appreciable enhancement of $\mathrm{MCh}$ depolarization as recorded in the sucrose gap (see also Materials

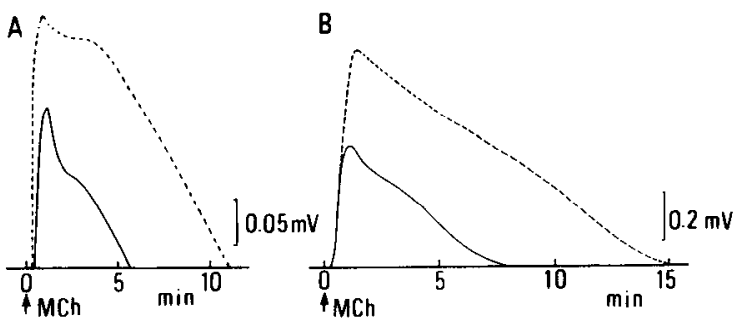

Figure 2. Long-term enhancement (LTE) action of ADTN and metoclopramide on the muscarinic slow depolarization elicited by $\mathrm{MCh}$. $A$, Depolarizing responses to a single injection of $\mathrm{MCh}(100 \mu \mathrm{g}$ in 0.1 $\mathrm{ml}$, giving roughly $300 \mu \mathrm{M}$ concentration in the chamber) before (solid line) and $30 \mathrm{~min}$ after (dashed line) exposure of the ganglion to $15 \mu \mathrm{M}$ ADTN for $8 \mathrm{~min}$ (without U-0521 and ascorbate). $B$, Depolarizing responses to $\mathrm{MCh}(50 \mu \mathrm{g}$ in $0.1 \mathrm{ml})$ before (solid line) and $60 \mathrm{~min}$ after (dashed line) exposure to $50 \mu \mathrm{M}$ metoclopramide for $15 \mathrm{~min}$ (without U-0521 and ascorbate).

and Methods), whereas it appeared capable of inducing a substantial LTE of orthodromic s-EPSP in the air gap (Ashe and Libet, 1981).

The degree of LTE of MCh test responses, expressed as the percentage increase over the amplitude of MCh depolarization before DA, was usually very similar for both ganglia of the pair excised from the same animal. In the experiments with 3 pairs of ganglia, both sides of a pair were identically treated by DA alone and the difference between increases in the amplitude of $\mathrm{MCh}$ depolarization in each of the 2 ganglia in a pair was determined. These differences produced a SEM of $\pm 1.8 \%$, with a normalization of each increase value in 1 side of the ganglia pair at $100 \%$, as illustrated in the top bar of Figure 4 ("No antagonist"). Actual increases with DA for different preparations, relative to the responses before DA, ranged from 20 to $100 \%$. In 39 ganglia, the average increase of the MCh depolarization following exposure to DA $(15 \mu \mathrm{M})$ was $69 \pm 9 \%$ (mean and SEM). The increased responsiveness to MCh fell off slowly (in repeated tests at $30 \mathrm{~min}$ intervals) over $3 \mathrm{hr}$ or more (see also Libet and Tosaka, 1970; Libet et al., 1975; Libet, 1979a).

The DA analog ADTN (2-amino-6,7-dihydroxy-1,2,3,4tetrahydronaphthalene; Woodruff et al., 1979) consistently induced the LTE of MCh depolarization (Fig. $2 A$ ) when administered in the same manner as DA. At an estimated concentration of $15 \mu \mathrm{M}$, the average increase in MCh depolarization was $49 \pm 4 \%$ in 3 experiments. When DA was tested on 1 of the paired ganglia and ADTN on the other, both at $15 \mu \mathrm{M}$, the LTE of MCh depolarization were roughly similar. ADTN tested in the absence of U-0521 (2 ganglia) induced LTEs roughly similar to those in the tests with U-0521.

Metoclopramide is known to be an antagonist of the DA-D receptor, the one not coupled to adenylate cyclase (Peringer et al., 1976; Roufogalis et al., 1976; Hyttel, 1978; Kebabian and Calne, 1979; Kebabian et al., 1984). Surprisingly, exposure to metoclopramide at $50 \mu \mathrm{M}$ (in the absence of U-0521) was found to induce LTE of the orthodromically elicited s-EPSP response (Ashe and Libet, 1982a). We also found in the present study that exposure to metoclopramide ( $50 \mu \mathrm{M}$ for $15 \mathrm{~min}$ with no U-0521) was followed by a large LTE of the test response of MCh depolarization (Fig. 2B); average change in the MCh depolarization was $+81 \pm 4 \%$ for 3 experiments. (Other known $D_{2}$ antagonists-sulpiride, even at $60 \mu \mathrm{M}$, and domperidone at 10 $\mu_{\mathrm{M}}-\mathrm{had}$ no enhancing or depressant effect on MCh depolarization; see below on Antagonists). 


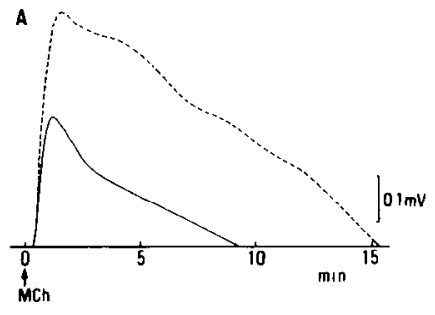

B

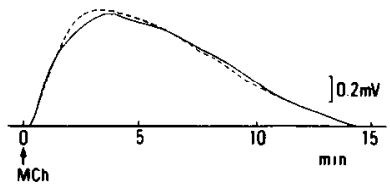

Figure 3. Depressant effect of (+)-butaclamol on the DA-induced LTE of muscarinic slow depolarization elicited by MCh. Records in $A$ and $B$ were taken from each of the paired ganglia, respectively, excised from the same animal. $A$, Control depolarizing responses to $\mathrm{MCh}(50 \mu \mathrm{g})$ before (solid line) and $30 \mathrm{~min}$ after (dashed line) exposure of the ganglion to $15 \mu \mathrm{M} \mathrm{DA}$ for $8 \mathrm{~min}$ (see Materials and Methods). $B$, Two responses to $\mathrm{MCh}$ recorded in the same way as in $A$, except for the presence of 7 $\mu \mathrm{M}(+)$-butaclamol beginning about $1 \mathrm{hr}$ before all MCh tests. Note that (+)-butaclamol did not depress the $\mathrm{MCh}$ response itself, but only prevented the enhancement normally producible by $\mathrm{DA}$; the somewhat elongated MCh response is within the normal range of variations in form (due to differences in the shape of the part of ganglion under sucrose gap, ctc.).

The potent $\alpha_{2}$-adrenergic agonists, $\alpha$-methylnorepinephrine (15 $\mu \mathrm{M})$ and clonidine $(15 \mu \mathrm{M})$, had no LTE effect at all on the $\mathrm{MCh}$ responses. However, $\beta$-adrenergic agonist isoproterenol (15 $\mu \mathrm{M}$, tested either with or without U-0521) appeared to have a definite enhancing effect on the $\mathrm{MCh}$ depolarization, although the evidence is not conclusive as to whether it is as effective as DA. Isoproterenol produced some enhancement in 9 out of 17 experiments. In 3 experiments, in which 1 paired ganglion was treated with DA and the other with isoproterenol (U-0521 absent for both), enhancements were similar (about $+88 \%$ ) after $30 \mathrm{~min}$; but the enhancement with isoproterenol fell off sharply thereafter, while that with DA remained high at 60 and 90 min.

\section{Pharmacological antagonists of the DA-induced LTE of muscarinic depolarization}

DA induction of LTE of slow muscarinic depolarization was antagonized by certain neuroleptic drugs, but not by $\alpha$ - or $\beta$-antagonists. An example of the effects of $(+)$-butaclamol on the actual changes in MCh depolarization after DA is shown in Figure 3. Results for experiments on similarly paired ganglia (both treated with DA but one in the presence of the antagonist drug) for all the other potential antagonists tested are summarized in Figure 4. At the concentrations tested, none of the antagonists produced any significant depression of the depolarizing response to $\mathrm{MCh}$ itself. (The point was tested by observing the control MCh depolarization before and after adding an antagonist, and also in separate experiments with no exposure to $\mathrm{DA}$, in which 1 ganglion of a pair received an antagonist and the subsequent MCh depolarization was compared for both ganglia.) The depressant effects shown in Figures 3 and 4 are thus specifically the reductions in the percentage of enhancement of MCh depolarization that follows exposure to DA in the paired ganglia without antagonists.

Fully adequate dose-response curves in the presence of each antagonist were not obtained, so that only crude inferences were made from the relatively small number of concentrations for the effectiveness of only $(+)$-butaclamol, which was found most effective among antagonists tested. It was almost fully (98\%) effective at $7 \mu \mathrm{M}(n=4)$, still $61 \%$ effective at $0.7 \mu \mathrm{M}(n=2)$, $22 \%$ effective at $0.2 \mu \mathrm{M}(n=2)$, but showed no depressant effect at $0.07 \mu \mathrm{M}(n=2)$. The $(-)$-enantiomer of butaclamol was

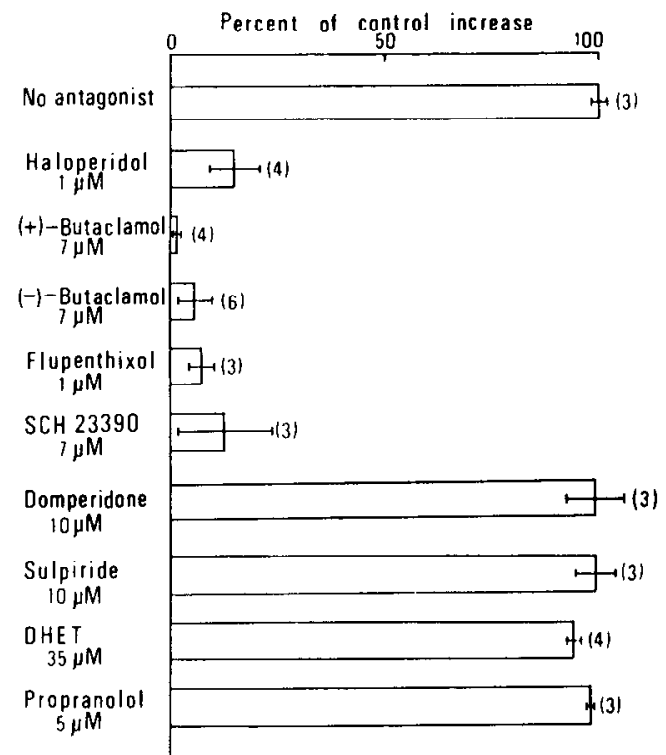

Figure 4. Comparison of effects of various antagonists on the DAinduced LTE of muscarinic slow depolarization by MCh. Percentage increases in the amplitudes of MCh responses after DA treatment were measured in the presence (test ganglion) and absence (control ganglion) of antagonists in parallel recordings from paired ganglia (see Materials and Methods). Each bar shows the fraction of enhancement still remaining in the presence of antagonists and expressed as the percentage of increase in the paired ganglion with no antagonist. Each bar also represents the mean value and SEM for the experiments (numbers in the parentheses) with each antagonist. Three experiments with no antagonist (the top bar with $S E M$ ) were separately done with only DA for both ganglia of the pairs.

approximately as effective as the (+)-enantiomer. (This was true even at reduced concentrations as low as $0.2 \mu \mathrm{M}$, but both were ineffective at $0.07 \mu \mathrm{M}$.)

Other DA antagonists that also depressed the DA-induced LTE of MCh depolarization with an effectiveness roughly comparable to that of butaclamol were haloperidol and flupenthixol, when tested at $1 \mu \mathrm{M}$. R-(+)-8-chloro-2,3,4,5-tetrahydro-3methyl-5-phenyl-1 H-3-benzazepine-7-ol (SCH-23390), reported to be a potent and selective antagonist against $D_{1}$ receptors for DA in other tissues (Iorio et al., 1983; Goldberg et al., 1984; Kebabian et al., 1986), appeared similarly effective. However, the relatively specific antagonists of $D_{2}$ receptors, sulpiride (Roufogalis et al., 1976; Kebabian and Calne, 1979), and domperidone (Denef and Follebouckt, 1978; Kebabian et al., 1984) were completely ineffective even at $10 \mu \mathrm{M}$ (Fig. 4). Similarly, the $\alpha$-adrenergic antagonist dihydroergotamine (even at the high concentration of $35 \mu \mathrm{M})$ and $\beta$-antagonist propranolol $(5 \mu \mathrm{M})$ had virtually no effect on the DA-induced change in MCh depolarization. Propranolol (even at $10 \mu \mathrm{M}$ ) did not depress the enhancing effect even of isoproterenol in 3 experiments.

\section{Stimulation of ganglionic CAMP synthesis by $D A$ and related substances}

cAMP content in one of the paired ganglia, simply after dissection from an animal and with $30 \mathrm{~min}$ stabilization, was found to be $21.42 \pm 1.25 \mathrm{pmol} / \mathrm{mg}$ protein (baseline value; $n=12$ ). With 90 min incubation of counterpart test ganglion at $37^{\circ} \mathrm{C}$ with theophylline ( $5 \mathrm{mM}$ ), also with Na-ascorbate $(300 \mu \mathrm{M})$ for the last $30 \mathrm{~min}$, cAMP content was essentially unchanged $(2 \pm$ 


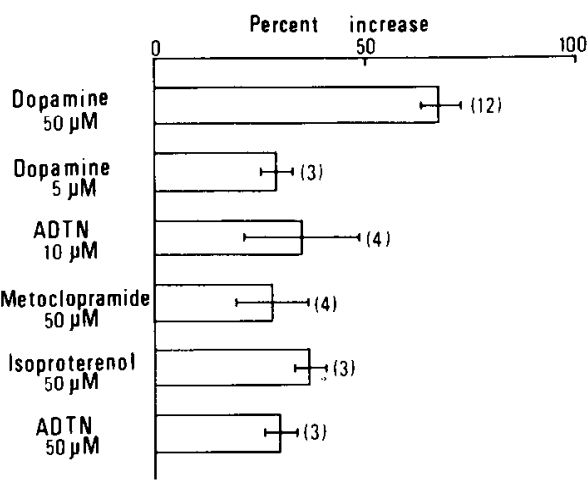

Figure 5. Induction of rise in cAMP content by treatment with DA and some other agents. Increase in 1 of the paired ganglia in response to an agent was compared with the cAMP levels in the contralateral ganglion without any treatment (baseline value) and expressed as the percentage increase over it (see Materials and Methods). Each bar represents the mean percentage difference and SEM for the pairs of ganglia tested (numbers in the parentheses) for each agent. COMT inhibitor U0521 was present during the treatment with DA $(5$ and $50 \mu \mathrm{M})$ and ADTN $(10 \mu \mathrm{M})$ but not for metoclopramide, isoproterenol, and ADTN $(50 \mu \mathrm{M})$. (See text for U-0521's own effect and significance here.)

$5 \%$ increase; $n=3$; see Table 1 ). With incubation with U-0521 $(300 \mu \mathrm{M})$ for the last $60 \mathrm{~min}$, together with the above theophylline and ascorbate, cAMP content showed only a small increase of $18 \pm 8 \%(n=3)$, as opposed to the baseline value. This increase with U-0521 seemed at least partially depressed by butaclamol.

With $30 \mathrm{~min}$ incubation of the paired (test) ganglion in the medium containing various concentrations of DA (1-50 $\mu \mathrm{M})$ and $\mathrm{U}-0521$ (as well as theophylline and $\mathrm{Na}$-ascorbate; see Materials and Methods) at $37^{\circ} \mathrm{C}$, consistent and dose-dependent increases in the accumulation of intraganglionic cAMP were observed (Figs. 1 and 5). Maximal increase was attained at about $50 \mu \mathrm{M}$ DA $(68 \pm 5 \%$ over the baseline value; $n=12$ : The difference was statistically significant, with $p<0.001$ ). At the much higher DA concentration of $200 \mu \mathrm{M}$, the increase in cAMP content fell off.

ADTN, tested under similar conditions-at $10 \mu \mathrm{M}$ with $\mathrm{U}-0521$ present-induced a mean percentage increase in cAMP content over that of paired control ganglia: $+35 \pm 14 \%(n=4$, $p<0.05)$. With U-0521 absent, ADTN at $50 \mu \mathrm{M}$ could also induce an increase of $30 \pm 4 \%(n=3, p<0.001)$. Although this shows that U-0521 is not essential in order for such agonists to stimulate adenylate cyclase, the values for ADTN and DA at $50 \mu \mathrm{M}$ should not necessarily be regarded as indicating a difference in potency, since U-0521 was present for DA throughout. [ADTN is also a good substrate for COMT, according to G. N. Woodruff (personal communication).]

Isoproterenol, tested at $50 \mu \mathrm{M}$ in the absence of $\mathrm{U}-0521$, also induced a substantial rise in cAMP content (mean percentage increase of $+37 \pm 4 \% ; n=3, p<0.001$ ). This is roughly similar to the increase with ADTN at $50 \mu \mathrm{M}$ without $\mathrm{U}-0521$ (see the Discussion).

Metoclopramide had been found in this study to induce an LTE of MCh depolarization, in a fashion similar to that of orthodromically produced s-EPSP responses (Ashe and Libet, 1982a). It was also found here to increase cAMP content; with metoclopramide at $50 \mu \mathrm{M}$ (without U-0521), the mean percentage increase in cAMP was $+28 \pm 9 \%(n=4, p<0.001)$.

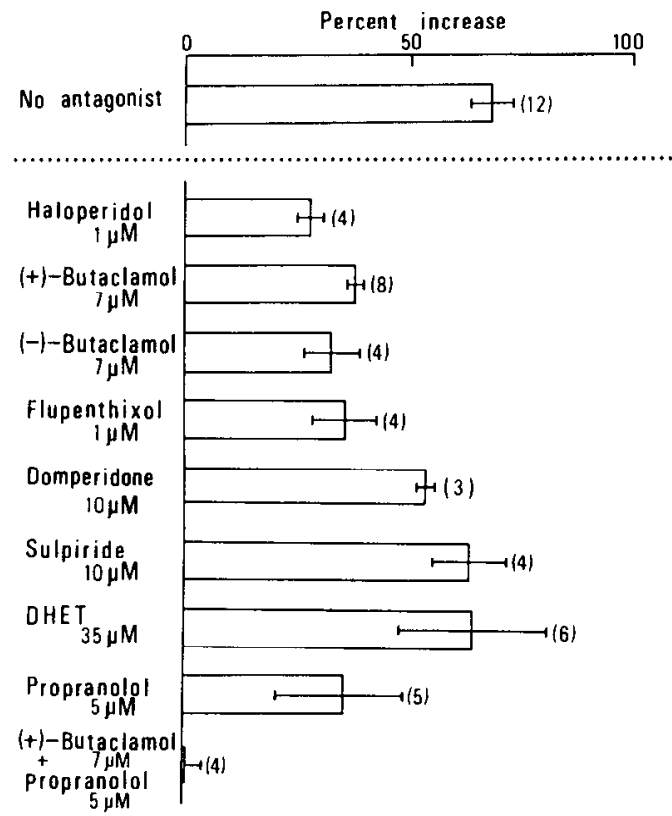

Figure 6. Effects of various antagonists on the increase in cAMP content induced by treatment with DA at $50 \mu \mathrm{M}$ (U-0521 present). As in the experiments with DA and no antagonists (Fig. 5), the increase in 1 of the paired ganglia treated with DA in the presence of an antagonist was compared with the level in the contralateral ganglion without DA and antagonist (baseline value) and was expressed as the percentage increase over the baseline level. Each bar gives mean percentage difference and SEM of pairs tested for each antagonist. These may be compared to the corresponding bar for DA with no antagonist (the top bar).

\section{Antagonists of the DA-stimulated synthesis of cAMP}

Those neuroleptic drugs that were shown to strongly antagonize the induction of LTE of MCh depolarization by DA were also shown to depress the elevation of ganglionic cAMP levels stimulated by DA (Fig. 6). Haloperidol (1 $\mu \mathrm{M}),(+)$ - and (-)-butaclamol $(7 \mu \mathrm{M})$, and flupenthixol $(1 \mu \mathrm{M})$ all reduced the DAinduced increase in cAMP by about $50 \%$; i.e., the mean increase of $68 \%$ following DA (50 $\mu \mathrm{M})$ without antagonist was reduced to about $35 \%$ in the presence of each of such antagonists. SCH$23390(7 \mu \mathrm{M})$ was tested in later, separate sets of experiments and was also found to depress a DA-induced increase in cAMP to about the same degree as did (+)-butaclamol. Sulpiride, domperidone, and dihydroergotamine, previously shown to be unable to prevent LTE of MCh depolarization by DA, were also relatively ineffective in depressing the $\mathrm{DA}$-induced increase in cAMP.

On the other hand, propranolol ( $5 \mu \mathrm{M})$, although found to be ineffective against the LTE of MCh depolarization by DA, did block almost $50 \%$ of the DA-induced rise in cAMP. We postulate that propranolol was antagonizing mostly a $\beta$-adrenergic component of the DA-induced increase in CAMP, and that such a component accounted for the incomplete blockade by the neuroleptic drugs of the adenylate cyclase response to DA. To test the validity of this hypothesis for 2 different mediating receptors whose effects in increasing the cAMP content of the whole ganglion could be additive, we applied a combination of (+)-butaclamol $(7 \mu \mathrm{M})$ and propranolol $(5 \mu \mathrm{M})$. This combination of antagonists did in fact completely eliminate the DAinduced increase in cAMP. This latter result was shown to be not due simply to the need for a higher total concentration of 
antagonists for maximal blockade of a single receptor; $(+)$-butaclamol alone raised to $15 \mu \mathrm{M}(n=4)$ was found to be no more effective than at $7 \mu \mathrm{M}$.

\section{Discussion}

The present investigation provides strong support for the view that modulatory long-term enhancement (LTE) of slow muscarinic responses by DA in the rabbit superior cervical ganglion is mediated by a specific DA receptor, in particular, one that is coupled to activation of adenylate cyclase (Libet et al., 1975; Kobayashi et al., 1978; Libet, 1979b). In the present experiments, both of the effects that follow exposure to DA (LTE of slow muscarinic depolarization and a rise in cAMP content) were studied in the same tissue and with similar concentrations of potential agonists and antagonists for both actions. As illustrated in Figure 1, both of the above effects were shown to occur in the same range of DA concentration, but the dose-response curves for those 2 events were somewhat different in shape. Somc diffcrences in the experimental conditions for LTE tests and cAMP assays may help to account for the difference in the shapes of the dose-response curves: (1) LTE tests were performed at room temperature, while cAMP assays were at $37^{\circ} \mathrm{C}$, and (2) the penetration of DA deep into the ganglion may be required for a detectable increase in cAMP in the whole ganglion, while it is not essential for the LTE, as the electrical activities of only superficially located neurons are usually monitored in the sucrose-gap recording. Even with U-0521 alone, there was some increase of CAMP, while no LTE was produced (Fig. 1). This discrepancy may be due particularly to the differences in temperature between the above 2 types of experiments. At room temperature, the spontaneous release of endogenous DA would be negligible and therefore U-0521 alone would not help to increase cAMP content and to induce LTE. At a concentration of exogenous DA between 1 and $5 \mu \mathrm{M}$, cAMP started to increase further beyond the level with U-0521 alone. This may correspond to the fact that U-0521 alone was able to induce some LTE of orthodromic s-EPSP in the air-gap experiments (which were carried out at $37^{\circ} \mathrm{C}$ ), and exogeneous DA (50 $\left.\mu \mathrm{M}\right)$ caused a further increase in the s-EPSP (Ashe and Libet, 1981). In the same range of DA as above, the LTE of MCh depolarization became evident (Fig. 1). This agreement in the effective concentration, in spite of the difference in temperaturc, may support the view that the exogenously applied DA would induce the LTE by stimulating adenylate cyclase. Another characteristic difference in the shape of dose-response curves in Figure 1 may reflect differences in the cellular mechanism of the LTE and cAMP increases: It is possible that DA can stimulate the production of more cAMP than is necessary for a maximal LTE. This would make the DA concentration for the half-maximal increase in cAMP greater than that for the half-maximal induction of LTE. Furthermore, our findings in the present study that about a half of the DA stimulation of cAMP may be due to DA action on $\beta$-adrenergic receptors, and may not be related to LTE, would also account for the difference in the two doseresponse curves in Figure 1.

Those agonists found to be effective for LTE of MCh depolarization were also capable of inducing a substantial rise in cAMP content; they were DA, ADTN, and mctoclopramide. Conversely, those antagonist drugs that depressed the DA-induced LTE of MCh depolarization were also found to be capable of depressing the DA-induced rise in cAMP content; these in- cluded butaclamol, haloperidol, flupenthixol, and SCH-23390, all regarded as antagonists of specific DA receptors (Seeman, 1980; Kcbabian et al., 1986). The inability of these agents to suppress the increase in cAMP as fully as they did the LTE of $\mathrm{MCh}$ depolarization is discussed below, with $\beta$-adrenergic actions. A discrepancy between the ability of propranolol to depress about a half of the increase in cAMP and its complete inability to depress the LTE will also be discussed. Antagonists of $\alpha$-adrenergic receptors (dihydroergotamine) and those more selectively antagonistic to the $\mathrm{D}_{2}$ receptor (sulpiride and domperidone) were without effect on either of the DA actions under study.

DA can also induce a direct postsynaptic hyperpolarizing response during application to the ganglion (as previously shown for DA by Libet and Tosaka, 1970; Dun and Nishi, 1974). This action is mediated by $\alpha_{2}$-adrenergic receptors (Brown and Caulfield, 1979; Mochida et al., $1981 \mathrm{a}$; Ashe and Libet, 1982b) and appears to be unrelated to DA induction of LTE for muscarinic slow depolarizing responses: (1) The hyperpolarizing response is over within a few minutes, long before the next test with MCh; (2) the enhancing effect is obtainable with lower doses of DA that elicit no hyperpolarization at all (Libet and Tosaka, 1970); (3) neither $\alpha$-methylnorepinephrine nor clonidine (15 $\mu \mathrm{M})$ produced any enhancement of MCh depolarization, even though they can elicit a large hyperpolarizing response; and (4) metoclopramide $(50 \mu \mathrm{M})$ produced no hyperpolarization but did induce enhancement of MCh depolarization.

The DA receptor mediating the LTE action of DA in the rabbit SCG resembles, but appears not to be identical with, the $D_{1}$ type described for striatal tissue in the brain (Hyttel, 1978, 1983; Kebabian and Calne, 1979; Seeman, 1980; Kebabian et al., 1984). Like the brain receptor, the DA receptor in these ganglia is coupled to activation of adenylate cyclase, and antagonists of such an activation in the striatum also antagonize both the stimulation of adenylate cyclase and the enhancement of MCh depolarization by DA in the SCG. These include the antagonist SCH-23390, which, although highly selective for $D_{1}$ receptors in the brain (Iorio et al., 1983; Kebabian et al., 1986), is actually no more potent than some of the mixed $D_{1} / D_{2}$ antagonists (including haloperidol at $1 \mu \mathrm{M}$ ) against the DA cyclase effect (Hyttel, 1983), as is the case with ganglia. Selective $D_{2}$ antagonists (sulpiride and domperidone) did not depress DA actions in ganglia. Metoclopramide, at a $10 \mu \mathrm{M}$ concentration that is effective as a $\mathrm{D}_{2}$ antagonist in brain tissue, also had no effect on DA-induced LTE (Ashe and Libet, 1982a); at higher concentrations, it behaved like an agonist (see below). On the other hand, the ganglionic DA receptor exhibits some properties at variance with those described for the striatal $D_{1}$ receptor: (1) The ganglionic receptor shows no stereoscopic specificity for the $(+)$ - as opposed to the (-)-isomer of butaclamol, whether in testing DA induction of LTE for MCh depolarization (and for orthodromic s-EPSP responses; Ashe and Libet, 1981) or in testing DA stimulation of adenylate cyclase. This contrasts with the sharp stereospecificity found in the striatum, etc. (Lippmann et al., 1975; Miller et al., 1975; Hyttel, 1978). A similar absence of stereospecificity for butaclamol was shown for the inhibition of ATP-dependent ${ }^{3} \mathrm{H}$-DA binding in bovine caudatum at about $7 \mu \mathrm{M}$, a concentration similar to that used in the present study (Near and Mahler, 1982). However, it was claimed that this DA binding was unrelated to the activation of adenylate cyclase, in contrast to our present results, which show a suppression of DA 
activation of adenylate cyclase by either stereoisomer of butaclamol. (2) Metoclopramide in higher concentrations (50 $\mu \mathrm{M}$ or more) mimics both of the DA actions in ganglia; but metoclopramide did not activate adenylate cyclase in the striatum, even at 50-200 $\mu \mathrm{M}$ (Roufogalis et al., 1976). (3) The $\beta$-agonist isoproterenol appears to be able to activate the ganglionic DA receptor (see below); we do not know whether such an ability has been excluded for the striatal $D_{1}$ receptor. Whether $D_{1}$ receptors, with somewhat different features from the ganglionic one, also exist in some other, as yet untested, cerebral structures is presently an open question.

The issue of any potential role for a $\beta$-adrenergic receptor in the ganglion is a complicated one and can lead to misinterpretations about the role of DA as well. The stimulation of adenylate cyclase via a $\beta$-receptor in the sympathetic ganglia of rats was already well known (Cramer et al., 1973; Lindl and Cramer, 1975; Brown et al., 1979; Lindl, 1979). Those studies were done with no COMT inhibitor present; this may in part account for their inability to find substantial rises in cAMP with DA. DA presumably acts on postsynaptic $D_{1}$-like receptors protected by COMT (Ashe and Libet, 1981), while some large part of the $\beta$-action may possibly be exerted through the $\beta$-receptors on non-neuronal elements, like satellite cells (Ariano et al., 1982), which may not have significant COMT barriers. While DA in the absence of COMT inhibitor did induce large increases in cAMP in slices of bovine SCG (Kebabian and Greengard, 1971; Roch and Kalix, 1975), very small or almost no increases have been reported for DA applied to whole SCGs of rat (Cramer et al., 1973; Brown et al., 1979; Lindl, 1979) or rabbit (Kalix et al., 1974). The larger increase in cAMP content with $50 \mu \mathrm{M}$ DA than with $5 \mu \mathrm{M} \mathrm{DA}, 50 \mu \mathrm{M}$ ADTN, or isoproterenol may suggest that both DA-specific and $\beta$-adrenergic actions are additively involved in the action of higher concentrations of DA on adenylate cyclase in the rabbit SCG. In fact, approximately $50 \%$ of the rise in cAMP following $50 \mu \mathrm{M} \mathrm{DA}$, with U-0521 present, was resistant to the DA antagonists but could be eliminated by the further addition of the $\beta$-antagonist propranolol (Fig. 6). It appears, then, DA can activate the $\beta$ - as well as " $D_{1}$ " receptor in this tissue. Wamsley et al. (1980) had found that DA could elicit a substantial increase in cAMP content of the whole rabbit SCG, without having COMT inhibitor present (see also Williams et al., 1980); the present evidence suggests the possibility that some large fraction of that increase in cAMP by DA may have been mediated via a $\beta$-receptor, as Wamsley et al. (1980) apparently did not subject that DA effect to the $\beta$-antagonist propranolol. Conclusions based on findings of relative ineffectiveness of DA in stimulating adenylate cyclase must be reviewed in relation to (1) the need for a COMT inhibitor for adequate access to postsynaptic $\mathrm{D}_{1}$ receptors (see also Ashe and Libet, 1981) and (2) the potential ability of DA to activate $\beta$-receptors in ganglia or other neural structures

Isoproterenol appeared to produce some Li $\mathrm{E}$ of muscarinic slow depolarization. However, since propranolol had no effect on this LTE action by isoproterenol (or by DA), the action is presumably not mediated by the $\beta$-receptor. This contrasts with a $\beta_{2}$-receptor-mediated facilitation of ganglionic transmission in rat SCG (Brown and Dunn, 1983) and also with a $\beta$-adrenergic long-term facilitation of peptidergic transmission in guinca-pig inferior mesenteric ganglia (Dun et al., 1984); both effects were evidently blocked by propranolol. Instead, one might suggest that isoproterenol can, at least to some degree, activate the postsynaptic $D_{1}$-type receptor in the rabbit SCG, just as DA (at $50 \mu \mathrm{M}$ ) appears able to activate a $\beta$-receptor here. (Future testing of DA antagonists, like butaclamol, against isoproterenol-induced LTE would help to clarify this issue further.) It may be worth noting further that isoproterenol can also activate the $\alpha_{2}$ adrenergic receptor in ganglia and induce a hyperpolarizing response (Mochida et al., 1981a). That the multiple effects of DA and isoproterenol thus observed are not all on a single receptor is indicated by the differential effects of DA versus $\beta$-antagonists for each component of action.

From the foregoing lines of evidence, one may conclude that it is specifically the DA receptor coupled to adenylate cyclase that mediates the LTE action by DA on the muscarinic postsynaptic responses, and that the $\beta$-receptor does not mediate this LTE, even though its activation also leads to an increase in ganglionic cAMP. While cAMP derived via the DA receptor would mediate the LTE process (Libet et al., 1975; Kobayashi et al., 1978; Libet, 1979b), the cAMP derived from $\beta$-activation would be ineffective. The latter could be explained if the $\beta$-receptors were located on non-neuronal elements; or, if they were located on ganglion cells, the cAMP so produced might be sequestered and not have access to the intracellular sites that mediate the enduring change in muscarinic responsiveness. Previous suggestions that the DA-induced LTE action (Libet and Tosaka, 1970) and the DA stimulation of adenylate cyclase (Kebabian and Greengard, 1971; Kalix et al., 1974) were mediated by an $\alpha$-adrenergic receptor were based on the depressant effects of phenoxybenzamine or on a high concentration of phentolamine; such effects by these antagonists can now be explained differently by an additional action, unrelated to the $\alpha$-adrenergic antagonism (Walton et al., 1978). Another $\alpha$-antagonist, dihydroergotamine, even in relatively high concentrations had no effect on LTE or on cAMP increases by DA.

Although $D_{1}$ receptors (coupled to adenylate cyclase) are plentiful in certain cerebral structures (e.g., Miller et al., 1975; Kebabian and Calne, 1979), little is definitely known about their specific synaptic functions. The presently established role for such a receptor in the rabbit SCG offers a model for a modulatory role in synaptic transmission that could be tested for $D_{1}$ actions in the brain.

\section{References}

Ariano, M. A., C. A. Briggs, and D. A. McAfee (1982) Cellular localization of cyclic nucleotide changes in rat superior cervical ganglion. Cell. Mol. Neurobiol. 2: 143-156.

Ashe, J. H., and B. Libet (1979) A noradrenergic s-IPSP in mammalian sympathetic ganglion, elicited by a non-muscarinic action of preganglionic volleys. Soc. Neurosci. Abstr. 5: 735.

Ashe, J. H., and B. Libet (1981) Modulation of slow postsynaptic potentials by dopamine, in rabbit sympathetic ganglia. Brain Res. 217: 93-106.

Ashe, J. H., and B. Libet (1982a) Metoclopramide mimics D-1 type action of dopamine in rabbit superior cervical ganglion. Neuropharmacology 21: 429-431.

Ashe, J. H., and B. Libet (1982b) Pharmacological properties and monoaminergic mediation of the slow IPSP, in mammalian sympathetic ganglion. Brain Res. 242: 345-349.

Brown, D. A., and M. P. Caulfield (1979) Hyperpolarizing ' $\alpha{ }_{2}$ 'adrenoceptors in rat sympathetic ganglia. $\mathrm{Br}$. J. Pharmacol. 65 . 435-445.

Brown, D. A., and P. M. Dunn (1983) Depolarization of rat isolated superior cervical ganglia mediated by $\beta_{2}$-adrenoceptors. Br. J. Pharmacol. 79: 429-439.

Brown, D. A., M. P. Caulfield, and P. J. Kirby (1979) Relation between catecholamine-induced cyclic AMP changes and hyperpolarization in 
isolated rat sympathetic ganglia. J. Physiol. (Lond.) 290: 441-451.

Cramer, H., D. G. Johnson, I. Hanbauer, S. D. Silberstein, and I. J. Kopin (1973) Accumulation of adenosine 3',5'-monophosphate induced by catecholamines in the rat superior cervical ganglion in vitro. Brain Res. 53: 97-104.

Denef, C., and J.-J. Follebouckt (1978) Differential effects of dopamine antagonists on prolactin secretion from cultured rat pituitary cells. Life Sci. 23: 431-436.

Dun, N. J., and S. Nishi (1974) Effects of dopamine on the superior cervical ganglion of the rabbit. J. Physiol. (Lond.) 239: 155-164.

Dun, N. J., Z. G. Jiang, and N. Mo (1984) Long-term facilitation of peptidergic transmission by catecholamines in guinea-pig inferior mesenteric ganglia. J. Physiol. (Lond.) 357: 37-50.

Gilman, A. G. (1970) Protein binding assay for adenosine 3',5'-monophosphate. Proc. Natl. Acad. Sci. USA 67: 305-312.

Goldberg, L. I., D. Glock, J. D. Kohli, and A. Barnett (1984) Separation of peripheral dopamine receptors by a selective DA-1 antagonist, SCH-23390. Hypertension 6: I-25-I-30.

Hyttel, J. (1978) Effects of neuroleptics on ${ }^{3} \mathrm{H}$-haloperidol and ${ }^{3} \mathrm{H}$-cis(z)-flupenthixol binding and on adenylate cyclase activity in vitro. Life Sci. 23: 551-556.

Hyttel, J. (1983) SCH-23390: The first selective dopamine D-1 antagonist. Eur. J. Pharmacol. 91: 153-154.

Iorio, L. C., A. Barnett, F. H. Heitz, V. P. Houser, and C. A. Korduba (1983) SCH-23390, a potent benzazepine antipsychotic with unique interactions on dopamine system. J. Pharmacol. Exp. Ther. 226:462468.

Kalix, P., D. A. McAfee, M. Schorderet, and P. Greengard (1974) Pharmacological analysis of synaptically mediated increase in cyclic adenosine monophosphate in rabbit superior cervical ganglion. J. Pharmacol. Exp. Ther. 188: 676-687.

Kebabian, J. W., and D. B. Calne (1979) Multiple receptors for dopamine. Nature 277: 93-96.

Kebabian, J. W., and P. Greengard (1971) Dopamine-sensitive adenyl cyclase: Possible role in synaptic transmission. Science 174: 13461349.

Kebabian, J. W., M. Beaulieu, and Y. Itoh (1984) Pharmacological and biochemical evidence for the existence of two categories of dopamine receptors. Can. J. Neurol. Sci. 11 (Suppl.): 114-117.

Kebabian, J. W., T. Agui, J. C. van Oene, K. Shigematsu, and J. M. Saavedra (1986) The $D_{1}$ dopamine receptor: New perspectives. Trends Pharmacol. Sci. 7: 96-99.

Kobayashi, H., T. Hashiguchi, and N. S. Ushiyama (1978) Postsynaptic modulation of excitatory process in sympathetic ganglia by cyclic AMP. Nature 271: 268-270.

Kobayashi, H., S. Mochida, T. Tosaka, and B. Libct (1982) Characterization of two independent dopamine receptors in rabbit sympathetic ganglia. Neurosci. Lett. 9: S-80.

Kosterlitz, H. W., G. M. Lees, and D. I. Wallis (1968) Resting and action potentials recorded by the sucrose-gap method in the superior cervical ganglion of the rabbit. J. Physiol. (Lond.) 195: 39-53.

Libet, B. (1970) Generation of slow inhibitory and excitatory postsynaptic potentials. Fed. Proc. 29: 1945-1956.

Libet, B. (1979a) Slow postsynaptic actions in ganglionic functions. In Integrative Function of the Autonomic Nervous System, C. M. Brooks, K. Koizumi, and A. Sato, eds., pp. 197-222, U. Tokyo P. and Elsevier/North-Holland, Tokyo and Amsterdam.

Libet, B. (1979b) Which postsynaptic action of dopamine is mediated by cyclic AMP? Life Sci. 24: 1043-1058.

Libct, B., and C. Owman (1974) Concomitant changes in formaldehyde-induced fluorescence of dopamine interneurones and slow inhibitory postsynaptic potentials of the rabbit superior cervical ganglion, induced by stimulation of preganglionic nerve or by a muscarinic agonist. J. Physiol. (Lond.) 237: 635-662.

Libet, B., and T. Tosaka (1970) Dopamine as a synaptic transmitter and modulator in sympathetic ganglia: A different mode of synaptic action. Proc. Natl. Acad. Sci. USA 67: 667-673.

Libet, B., H. Kobayashi, and T. Tanaka (1975) Synaptic coupling into the production and storage of a neuronal memory trace. Nature 258: 155-157.
Lindl, T. (1979) Cyclic AMP and its relation to ganglionic transmission: A combined biochemical and electrophysiological study of the rat superior cervical ganglion in vitro. Neuropharmacology 18: 227235.

Lindl, T., and H. Cramer (1975) Evidence against dopamine as the mediator of the rise of cyclic AMP in the superior cervical ganglion of the rat. Biochem. Biophys. Res. Commun. 65: 731-739.

Lippmann, W., T. Pugsley, and J. Merker (1975) Effect of butaclamol and its enantiomers upon striatal homovanilic acid and adenyl cyclase of olfactory tubercle in rats. Life Sci. 16: 213-224.

Lowry, O. H., N. J. Rosenbrough, A. L. Farr, and R. J. Randall (1951) Protein measurement with the Folin-phenol reagent. J. Biol. Chem. 193: 265-275.

Miller, R. J., A. S. Horn, and L. L. Iversen (1975) Effect of butaclamol on dopamine-sensitive adenylate cyclase in the rat striatum. J. Pharm. Pharmacol. 27: 212-213.

Mochida, S., and B. Libet (1983) Long-term enhancement (LTE) of slow EPSP, induced by a physiological preganglionic train, cither homo- or heterosynaptically. Soc. Neurosci. Abstr. 9: 1212.

Mochida, S., and B. Libet (1985) Synaptic long-term enhancement (LTE) induced by a heterosynaptic neural input. Brain Res. 329: 360363.

Mochida, S., H. Kobayashi, T. Tosaka, and J. Tasaka (1981a) Dopamine receptors mediating two different actions in the rabbit sympathetic ganglia. J. Physiol. Soc. Jpn. 43: 298.

Mochida, S., H. Kobayashi, T. Tosaka, J. Ito, and B. Libet (1981b) Specific dopamine receptor mediates the production of cyclic AMP in the rabbit sympathetic ganglia and thereby modulates the muscarinic postsynaptic responses. Adv. Cyclic Nucleotide Res. 14: 685.

Near, J. A., and M. R. Mahler (1982) Low affinity, adenosine 5'triphosphate-dependent $\left[{ }^{3} \mathrm{H}\right]$-dopamine binding in synaptic membrancs from bovinc caudatc is unrclated to dopaminc-stimulated adenylate cyclase. J. Neurosci. 2: 553-561.

Peringer, E., P. Jenner, I. M. Donaldson, C. D. Marsden, and R. Miller (1976) Metoclopramide and dopamine receptor blockade. Neuropharmacology 15: 463-469.

Roch, P., and P. Kalix (1975) Effects of biogenic amines on the concentration of adenosine $3^{\prime}, 5^{\prime}$-monophosphate in bovine superior cervical ganglion. Neuropharmacology 14: 21-29.

Roufogalis, B. D., M. Thornton, and D. N. Wade (1976) Specificity of the dopamine-sensitive adenylate cyclase for antipsychotic antagonists. Life Sci. 19: 927-934.

Seeman, P. (1980) Brain dopamine receptors. Pharmacol. Rev. 32: 229-313.

Tanaka, T. (1974) Analysis of K-dependent electrogenic Na-pump in superior cervical ganglion of the rabbit. J. Tokyo Med. Coll. 32: 11011118.

Wallis, D. I., G. M. Lees, and H. W. Kosterlitz (1975) Recording resting and action potentials by the sucrose-gap method. Comp. Biochem. Physiol. 50C: 199-216.

Walton, K. G., P. Liepmann, and R. J. Baldessarini (1978) Inhibition of dopamine-stimulated adenylate cyclase activity by phenoxybenzamine. Eur. J. Pharmacol. 52: 231-234.

Wamsley, J. K., A. C. Black, Jr., J. R. West, and T. H. Williams (1980) Cyclic AMP synthesis in guinea-pig superior cervical ganglia: Response to pharmacological and preganglionic physiological stimulation. Brain Res. 182: 415-421.

Williams, T. H., A. C. Black, Jr., J. R. West, D. Sandquist, and N. Gluhbegovic (1980) Biochemical aspects of SIF cell function in guinea-pig and rabbit superior cervical ganglia. In Histochemistry and Cell Biology of Autonomic Neurons, SIF Cells and Paraneurons, $\mathrm{O}$. Eränkö, S. Soinila, and H. Päivärinta, eds., pp. 127-131, Raven, New York.

Woodruff, G. N., A. Davis, C. D. Andrews, and J. A. Poat (1979) Dopamine receptors in the mammalian brain. In Recent Advances in Receptor Chemistry, F. Gualtieri, M. Giannella, and C. Melchiorre, eds., pp. 165-188, Elsevier/North-Holland, Amsterdam. 